\title{
Mechanical Properties and Microstructural Evolution of T23 Heat-resistant Steel during Aging at 873K
}

\author{
Lili Wang ', Lihui Zhu '. Yongqing Deng ${ }^{i}$, Qijiang Wang ${ }^{2}$, Fengming Zou ${ }^{2}$ \\ 1. School of Materials Science and Engineering, Shanghai University, Shanghai 200072, China; \\ 2. Baoshan Iron and Steel Co., Ltd., Shanghai 201900, China
}

(Received November 24, 2007)

\begin{abstract}
In this paper, the mechanical properties and microstructural evolution of $\mathrm{T} 23(2.25 \mathrm{Cr}-1.6 \mathrm{~W}-\mathrm{V}-\mathrm{Nb})$ heat-resistant steel during aging at $873 \mathrm{~K}$ were investigated. The results show that the mechanical property degradation of $\mathrm{T} 23$ is related to the microstructural evolution during aging. There is an obvious decrease in yield strength and tensile strength when the aging time ranges from 0 to $1000 \mathrm{~h}$ and 5000 to $10000 \mathrm{~h}$. In the short-term region, the coarsening of $\mathrm{M}_{23} \mathrm{C}_{6}$ carbide results in the significant decrease in the yield strength and tensile strength, whereas for longterm aging the transformation of granular bainitic ferrite plays a main role. Compared with the as-supplied materials, the impact toughness of T23 aged for $10000 \mathrm{~h}$ decreases by $20 \%$, which results from the coarsening of $\mathrm{M}_{23} \mathrm{C}_{6}$ and the coalescence of bainitic ferrite laths.
\end{abstract}

Key words: heat-resistant steel, mechanical properties, microstructural evolution, aging

\section{INTRODUCTION}

Over the years, from the viewpoint of environmental protection and energy saving, higher-operating temperatures and pressures are used in power plants, and the advanced heat-resistant materials with high creep rupture strength and excellent comprehensive properties have been developed. Among these heatresistant steels, T23 $(2.25 \mathrm{Cr}-1.6 \mathrm{~W}-\mathrm{V}-\mathrm{Nb})$ used for boiler pressure parts exhibits extremely high creep rupture strength and superior weldability. The creep rupture strength of T23 is approximately twice stronger than conventional T22 $(2.25 \mathrm{Cr}-1 \mathrm{Mo})$ steel in the creep region over $823 \mathrm{~K}$ by substituting $\mathrm{W}$ for a part of Mo and adding some micro-alloying elements such as $\mathrm{V}, \mathrm{Nb}$ and $N$. Furthermore, the weldability of T23 steel is greatly improved and it can be used in as-welded condition without preheating and post-weld heat treatment $/ 1-7 /$.

It is well known that the mechanical properties of heat-resistant steels tend to degrade owing to microstructural evolution under elevated temperature. However, it is not clear that how the microstructural evolution affects the mechanical properties of T23 heatresistant steel during aging. In this paper, the mechanical properties and microstructural evolution of T23 steel during aging at $873 \mathrm{~K}$ were investigated and the effects of microstructural evolution on the yield strength, tensile strength and impact toughness were emphasized.

\section{MATERIALS AND EXPERIMENTAL PROCEDURE}

T23 steel tubes which were normalized and tempered were produced by Baoshan Iron and Steel Co., Ltd.. The chemical composition is given in Table 1. Aged at $873 \mathrm{~K}$ for $1000,3000,5000,8000$ and $10000 \mathrm{~h}$, respectively, the specimens were machined to carry out tensile test, Charpy impact test and hardness measurement. Especially, the specimens aged for 1000 , $5000,10000 \mathrm{~h}$ were chosen to study the effect of 
microstructural evolution on the mechanical property degradation. The microstructure of as-supplied and asaged T23 was examined by Nikon EPIPHOT 300 optical microscope (OM), S-570 scanning electron microscope (SEM) and JEM-200CX transmission electron microscope (TEM).

Table 1

Chemical composition of T23 steel (mass \%)

\begin{tabular}{lllllllllllll}
\hline $\mathrm{C}$ & $\mathrm{Cr}$ & $\mathrm{W}$ & $\mathrm{Mo}$ & $\mathrm{V}$ & $\mathrm{Nb}$ & $\mathrm{B}$ & $\mathrm{N}$ & $\mathrm{Mn}$ & $\mathrm{Si}$ & $\mathrm{Al}$ & $\mathrm{S}$ & $\mathrm{P}$ \\
\hline 0.08 & 2.33 & 1.52 & 0.17 & 0.24 & 0.04 & 0.004 & 0.012 & 0.48 & 0.25 & 0.011 & 0.008 & 0.009 \\
\hline
\end{tabular}

\section{RESULTS}

\subsection{Mechanical properties}

Figure 1 shows the variation of mechanical properties as a function of aging time. At the beginning of aging, yield strength and tensile strength decrease obviously, and then keep constant when aging time increases from 1000 to $5000 \mathrm{~h}$. After aged for $5000 \mathrm{~h}$, yield strength and tensile strength continue decreasing. Elongation and hardness slightly decrease with the increase of aging time.

Although the impact toughness fluctuates at the early stage of aging, it tends to decrease. After being aged for $10000 \mathrm{~h}$, the impact toughness decreases by $20 \%$ compared with the as-supplied T23, which is in agreement with the results of fractographs. The fracture surface of the samples aged for 1000 and $5000 \mathrm{~h}$ contains $100 \%$ fibrous regions, which consist of many deep dimples, as shown in Fig. 2a-b. After being aged for $10000 \mathrm{~h}$, the fracture surface is comprised of $80 \%$ fibrous regions and $20 \%$ crystalline regions. The fibrous regions still consist of many dimples (Fig. $2 \mathrm{c}$ ), while the quasi-cleavage fracture (Fig. 2d) is observed in the crystalline regions, indicating the decrease of impact toughness.

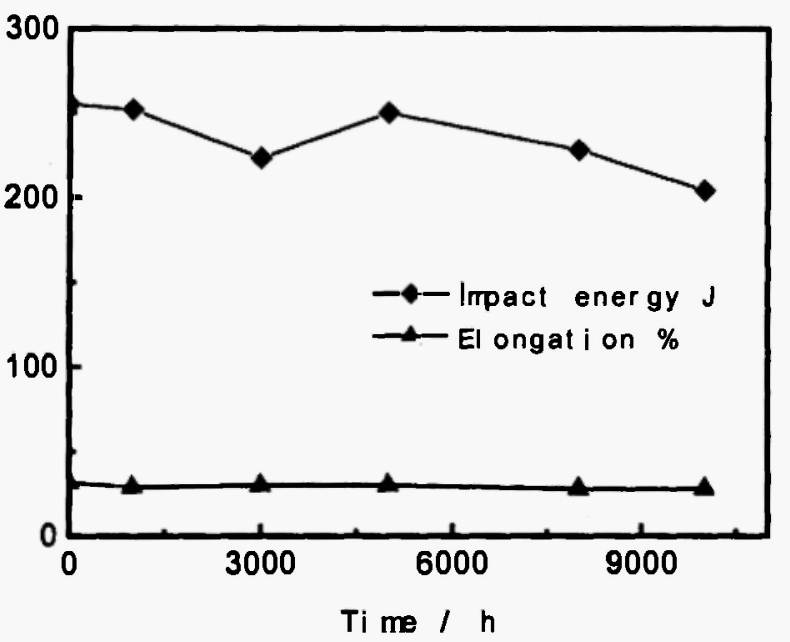

Fig. 1: Mechanical properties of T23 steel aged at $873 \mathrm{~K}$ 

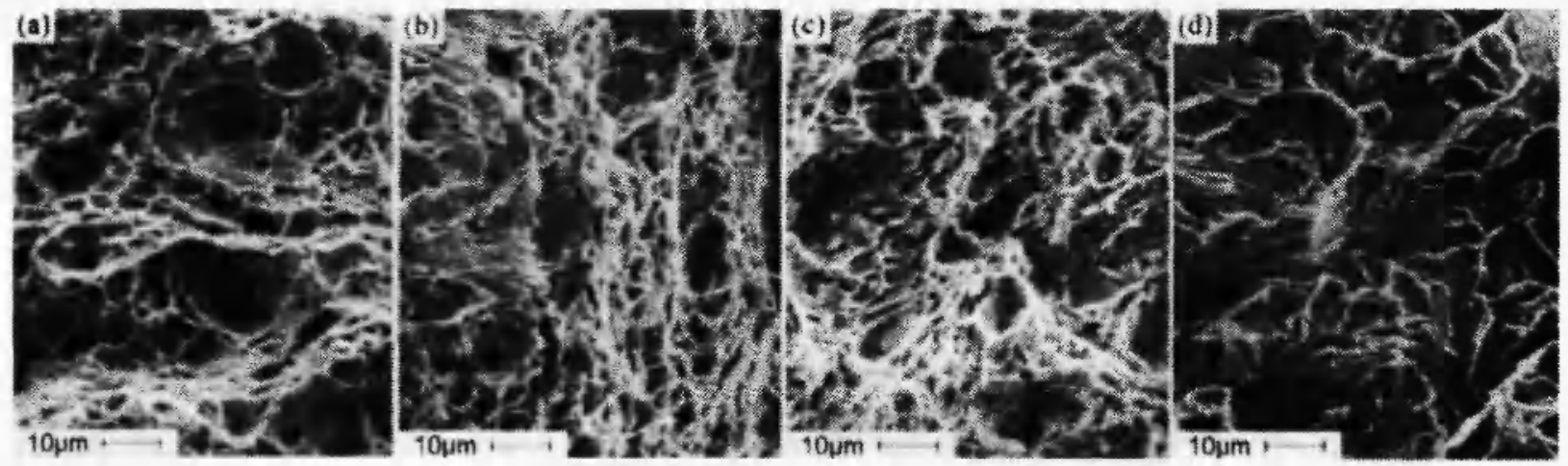

Fig. 2: Fractographs of T23 steel aged at $873 \mathrm{~K}$ (a) $1000 \mathrm{~h}$ (b) $5000 \mathrm{~h} \mathrm{(c),} \mathrm{(d)} 10000 \mathrm{~h}$.

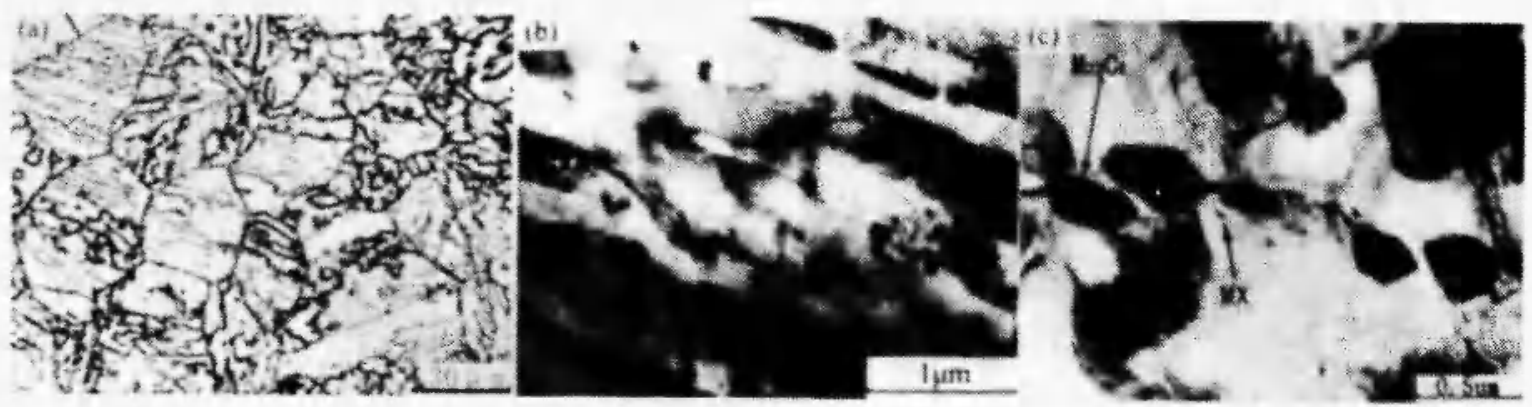

Fig. 3: Microstructure of as-supplied T23 steel (a) OM micrograph

(b), (c) TEM micrographs

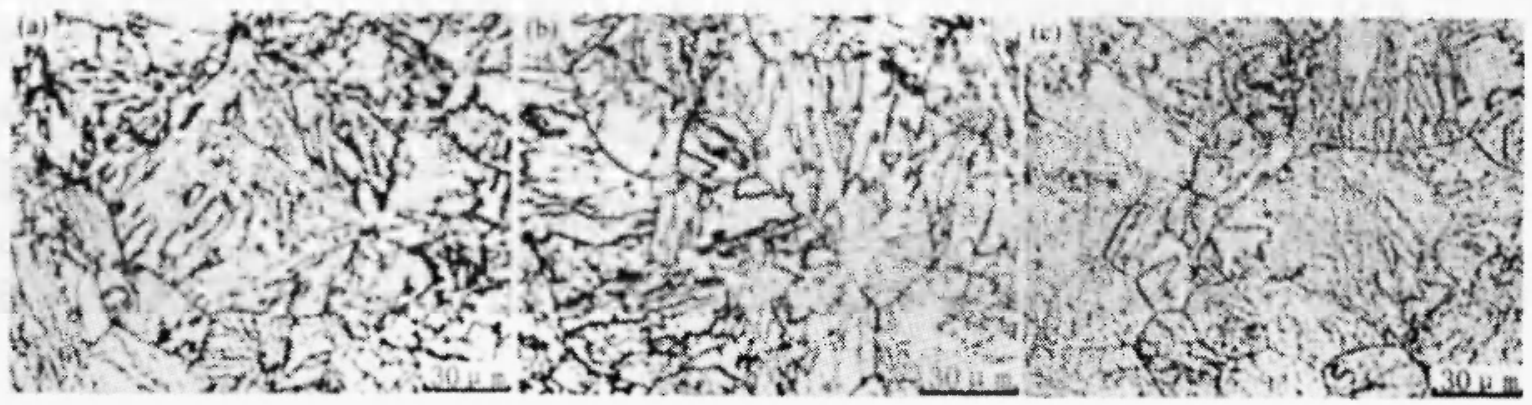

Fig. 4: Microstructure of T23 steel aged at $873 \mathrm{~K}$ (a) $1000 \mathrm{~h}$ (b) $5000 \mathrm{~h} \mathrm{(c)10000h.}$

\subsection{Microstructure}

As shown in Fig. 3a, the microstructure of assupplied T23 steel is granular bainite, where carbon-rich islands are randomly distributed in the bainitic ferrite matrix. Although there are a few polygonal ferrites, most bainitic ferrites take the form of laths /4/. TEM observation (Fig. $3 \mathrm{~b}$ ) further indicates that carbon-rich islands comprise martensite laths with a high dislocation density. The main precipitation particles within the matrix are found to be $\mathrm{M}_{23} \mathrm{C}_{6}$ carbides (approximately $50 \sim 175 \mathrm{~nm}$ in radius) and $\mathrm{MX}$ carbonitrides (approximately $5 \sim 15 \mathrm{~nm}$ in radius), which are distributed in grain interiors and grain boundaries (Fig. 3c). $\mathrm{M}_{23} \mathrm{C}_{6}$ contains mainly $\mathrm{Cr}, \mathrm{Mo}, \mathrm{W}$ and $\mathrm{Fe}$, while $\mathrm{MX}$ contains $\mathrm{Nb}, \mathrm{V}, \mathrm{C}$ and $\mathrm{N}$. In addition, a small amount of precipitations whose sizes are between $\mathrm{MX}$ and $\mathrm{M}_{23} \mathrm{C}_{6}$ are identified to be $\mathrm{M}_{7} \mathrm{C}_{3}$ carbides $/ 5 /$.

The microstructures of $\mathrm{T} 23$ steel aged at $873 \mathrm{~K}$ for 1000,5000 and $10000 \mathrm{~h}$ are shown in Fig. 4. It can be 
seen that the grain size slightly changes during aging at $873 \mathrm{~K}$. Compared with the as-supplied microstructure, there is no obvious change after aged for 1000 and 5000h (Fig. 4a-b). But when the aging time increases to $10000 \mathrm{~h}$ (Fig. 4c), many polygonal ferrites appear due to the coalescence of bainitic ferrite laths.
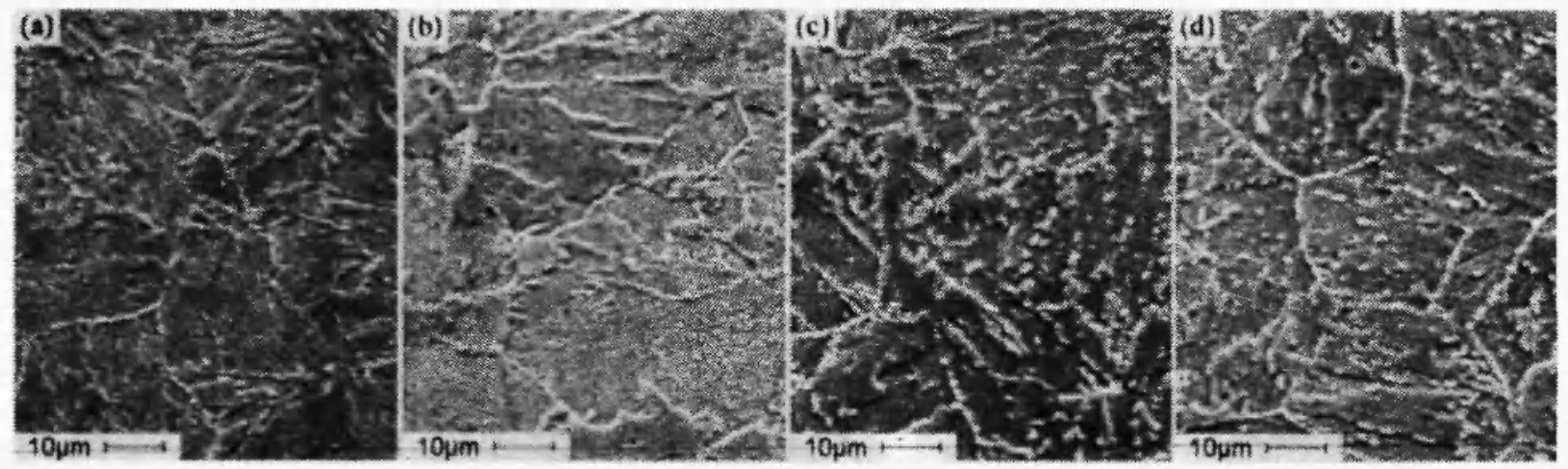

Fig. 5: SEM micrographs of T23 steel as-supplied and aged at $873 \mathrm{~K}$ (a) As-supplied (b) after aging for 1000h (c) after aging for $5000 \mathrm{~h}(\mathrm{~d})$ after aging for $10000 \mathrm{~h}$.
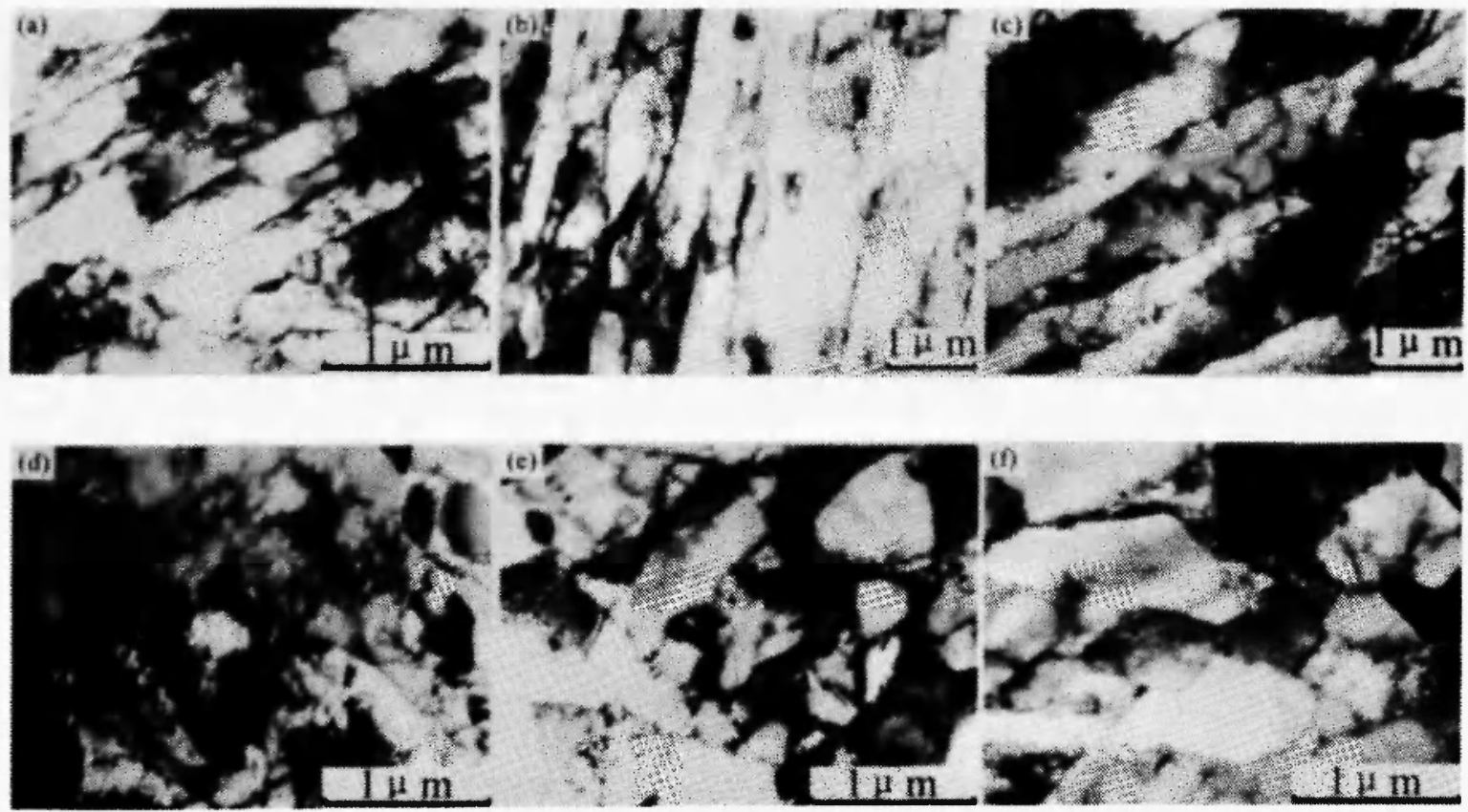

Fig. 6: TEM micrographs of T23 steel aged at $873 \mathrm{~K}$ (a) $1000 \mathrm{~h}$

(b) $5000 \mathrm{~h}$

(c) $10000 \mathrm{~h}$. (d) $1000 \mathrm{~h}$

(e) $5000 \mathrm{~h}$ $10000 \mathrm{~h}$

After aging at $873 \mathrm{~K}$, the precipitations are primarily $\mathrm{M}_{23} \mathrm{C}_{6}$ and $\mathrm{MX}$ by the analysis of electron diffraction patterns. Considering that $\mathrm{MX}$ carbonitrides are too fine to be observed by SEM, most of precipitations in Fig. 5 belong to $\mathrm{M}_{23} \mathrm{C}_{6}$. It is found that $\mathrm{M}_{23} \mathrm{C}_{6}$ carbides coarsen gradually with increasing aging time. For example, the average radius of $\mathrm{M}_{23} \mathrm{C}_{6}$ carbides in the as-supplied microstructure is $160 \mathrm{~nm}$, and it increases to $180 \mathrm{~nm}$ after aged for $1000 \mathrm{~h}$ and to $260 \mathrm{~nm}$ for $5000 \mathrm{~h}$. When the aging time increases to $10000 \mathrm{~h}, \mathrm{M}_{23} \mathrm{C}_{6}$ coarsens no longer, but the spheroidization of $\mathrm{M}_{23} \mathrm{C}_{6}$ can be observed. In addition, TEM observation shows that some $\mathrm{M}_{6} \mathrm{C}$ carbides are formed and there is a little change in the size and composition of MX during aging. 
As shown in Fig. 6, with increasing aging time, martensite laths in carbon-rich islands broaden slightly. The width of martensite laths after aged for $1000 \mathrm{~h}$ (Fig. 6a) is $0.35 \mu \mathrm{m}$, which approaches that of as-supplied microstructure. It increases to $0.6 \mu \mathrm{m}$ (Fig. 6b) and 0.85 $\mu \mathrm{m}$ (Fig. 6c) after aged for $5000 \mathrm{~h}$ and $10000 \mathrm{~h}$, respectively. In addition, the recovery and recrystallization of bainitic ferrite matrix occur during aging. A few subgrains are formed after aged for $5000 \mathrm{~h}$ and the amount increases with the aging time (Fig. 6df). There is a little change in the dislocation density because the dislocations can be pinned by MX carbonitrides effectively.

\section{DISCUSSION}

The yield strength $\left(\sigma_{y}\right)$ of the aged material has contributions from the precipitations, the solid solution and the intrinsic strength of steel, which can be expressed as $/ 8,9 /$ :

$$
\sigma_{y}=\sigma_{p p t}+\sigma_{s s}+\sigma_{i}
$$

$\sigma_{\mathrm{ppt}}-$ the contribution of precipitation hardening to the yield stress;

$\sigma_{\mathrm{ss}}$ - the contribution of solid solution strengthening to the yield stress;

$\sigma_{1}$-the contribution of the pure matrix to the yield stress.

As the samples are isothermally aged, $\sigma_{\mathrm{ppt}}$ is mainly dependent on the average radius and volume fraction of precipitations $/ 10 \%$. After being aged at $873 \mathrm{~K}$, the microstructure of T23 mainly consists of three types of precipitations, $\mathrm{MX}, \mathrm{M}_{23} \mathrm{C}_{6}$ and $\mathrm{M}_{7} \mathrm{C}_{3}$. The strong obstacle MX in T23 steel contributes little to the decrease of $\sigma_{\mathrm{ppt}}$ because the volume fraction and particle size of MX hardly change during aging at $873 \mathrm{~K} / 6,7 /$. Since there is a small amount of $\mathrm{M}_{7} \mathrm{C}_{3}$ in $\mathrm{T} 23$, the effect of $\mathrm{M}_{7} \mathrm{C}_{3}$ on $\sigma_{\mathrm{ppt}}$ can be ignored. Therefore, the decrease of $\sigma_{\mathrm{ppt}}$ for T23 steel during aging only depends on $\mathrm{M}_{23} \mathrm{C}_{6}$. According to the results of Kaori Miyata et al. on $0.06 \mathrm{C}-2.25 \mathrm{Cr}-1.6 \mathrm{~W}-0.1 \mathrm{Mo}-0.25 \mathrm{~V}-0.05 \mathrm{Nb} / 7 /$, there is a small change in the volume fraction of $\mathrm{M}_{23} \mathrm{C}_{6}$ during aging. In addition, our experimental results show that the size of $\mathrm{M}_{23} \mathrm{C}_{6}$ increases obviously during aging. Hence, the change of $\sigma_{p p t}$ is related to $M_{23} C_{6}$ size. T23 steel is regarded as in the condition of overaging since the yield strength decreases with increasing aging time, thus for non-shearable $\mathrm{M}_{23} \mathrm{C}_{6}$, the following equation can be used /10/:

$$
\sigma_{\mathrm{ppt}}=\mathrm{k} \mathrm{r}^{-1}
$$

where $\mathbf{k}$ is related to aging condition, $r$ is the radius of precipitations.

In this paper, $\mathrm{k}$ can be deemed to be constant, hence $\sigma_{\mathrm{ppt}}$ decreases with increasing particle size of $\mathrm{M}_{23} \mathrm{C}_{6}$. At the beginning of aging such as $0 \sim 1000 \mathrm{~h}$, the yield strength decreases from 543 to $514 \mathrm{MPa}$, although the size of $\mathrm{M}_{23} \mathrm{C}_{6}$ increases from 160 to $180 \mathrm{~nm}$. But the influence of $\mathrm{M}_{23} \mathrm{C}_{6}$ size on $\sigma_{\mathrm{ppt}}$ declines with increasing aging time from Eq. (2). When the aging time ranges from 1000 to $5000 \mathrm{~h}$, the size of $\mathrm{M}_{23} \mathrm{C}_{6}$ increases from 180 to $260 \mathrm{~nm}$, while the yield strength just decrease from 514 to $507 \mathrm{MPa}$, as shown in Fig. 7. In addition, the decrease of yield strength may also be accelerated by the spheroidization of $\mathrm{M}_{23} \mathrm{C}_{6}$.

$\sigma_{s s}$ is primarily related to the concentration of the solute atoms in the matrix. For T23 steel, solid solution strengthening is attributed mainly to $W$ and Mo elements $17,11 \%$. The results of Kaori MIYATA et al on $0.06 \mathrm{C}-2.25 \mathrm{Cr}-1.6 \mathrm{~W}-0.1 \mathrm{Mo}-0.25 \mathrm{~V}-0.05 \mathrm{Nb}$ have shown that the amount of $\mathrm{W}$ and $\mathrm{Mo}$ in the precipitations of the specimens normalized, aged for $3000 \mathrm{~h}$ and $10000 \mathrm{~h}$ is $0.15 \%, 0.3 \%$ and $0.55 \%$ (all in mass $\%$ ), respectively $/ 7 /$. In this study, the coarsening of $\mathrm{M}_{23} \mathrm{C}_{6}$ and the transformation from $\mathrm{M}_{23} \mathrm{C}_{6}$ to $\mathrm{M}_{6} \mathrm{C}$ also indicate that there are less and less $\mathrm{W}$ and $\mathrm{Mo}$ in the matrix during aging. But considering that the slight decrease of $W$ and Mo in the matrix does not result in the obvious decrease of yield strength, for T23 steel the reduction of $\mathrm{W}$ and Mo in the matrix during aging only accelerates the decrease of yield strength, as shown in Fig. 7.

$\sigma_{i}$ is affected by several factors, such as the grain size, microstructure and so on. In this study, there is a little change in the grain size and the dislocation density. But it is worth mentioning that the morphological evolution of the granular bainitic ferrites 
occurs during aging, which may affect the yield strength of T23 steel. With the thickening of ferrite sheaves, the bainitic ferrite laths of the same orientation coalesce, which leads to the formation of polygonal ferrites. Especially, more polygonal ferrites are obtained when aging time ranges from 5000 to $10000 \mathrm{~h}$. The yield strength of bainite will decrease as the amount and size of polygonal ferrites increase $/ 12,13 /$. Therefore, the decrease of yield strength for the aging time $5000 \sim 10000$ h mainly results from the transformation of granular bainitic ferrites, as shown in Fig. 7. Meanwhile, the martensite laths in carbon-rich islands broaden slightly and a few subgrains are formed during aging, which accelerate the decrease of yield strength.

Generally speaking, the yield strength degradation of T23 steel results from the changes of $\sigma_{\mathrm{ppt}}, \sigma_{\mathrm{ss}}$ and $\sigma_{\mathrm{i}}$. Fig. 7 shows the effect of microstructural evolution on yield strength of T23 during aging at $873 \mathrm{~K}$. In the short-term region, the coarsening of $\mathrm{M}_{23} \mathrm{C}_{6}$ carbides results in the significant decrease of yield strength whereas for longterm aging the transformation of granular bainitic ferrites plays a main role. The decrease of yield strength can also be accelerated by some factors such as the transformation from $\mathrm{M}_{23} \mathrm{C}_{6}$ to $\mathrm{M}_{6} \mathrm{C}$, the spheroidization of $\mathrm{M}_{23} \mathrm{C}_{6}$, the decrease of $\mathrm{W}$ and $\mathrm{Mo}$ in the matrix, the formation of subgrains and the broadening of martensite laths in carbon-rich islands.

Elongation reflects the plastic property of steel, which is related to the volume fraction and shape of carbides. On one hand, the amount of carbides increases due to the formation of $\mathrm{M}_{6} \mathrm{C}$ during aging at $873 \mathrm{~K} / 7 /$, possibly resulting in the increase of elongation. On the other hand, the spheroidization of $\mathrm{M}_{23} \mathrm{C}_{6}$ may lead to the decrease of elongation of T23 steel. Therefore, there is a minor change in the elongation of T23 during aging.

The tensile strength is primarily related to the yield strength and elongation. Therefore, the change of tensile strength is similar to that of yield strength due to a little change of elongation during aging at $873 \mathrm{~K}$ for T23 steel.

According to the E. Smith's nucleation theory of cleavage crack, it is easy for cleavage crack to nucleate and propagate when the carbides on the grain boundaries coarsen. When T23 steel is aged at $873 \mathrm{~K}$ for $10000 \mathrm{~h}, \mathrm{M}_{23} \mathrm{C}_{6}$ coarsens obviously and even the quasi- cleavage fracture can be observed, leading to the decrease of impact toughness. In addition, the decrease of impact toughness can be accelerated by the coalescence of bainitic ferrite laths, as shown in Fig. 7 .

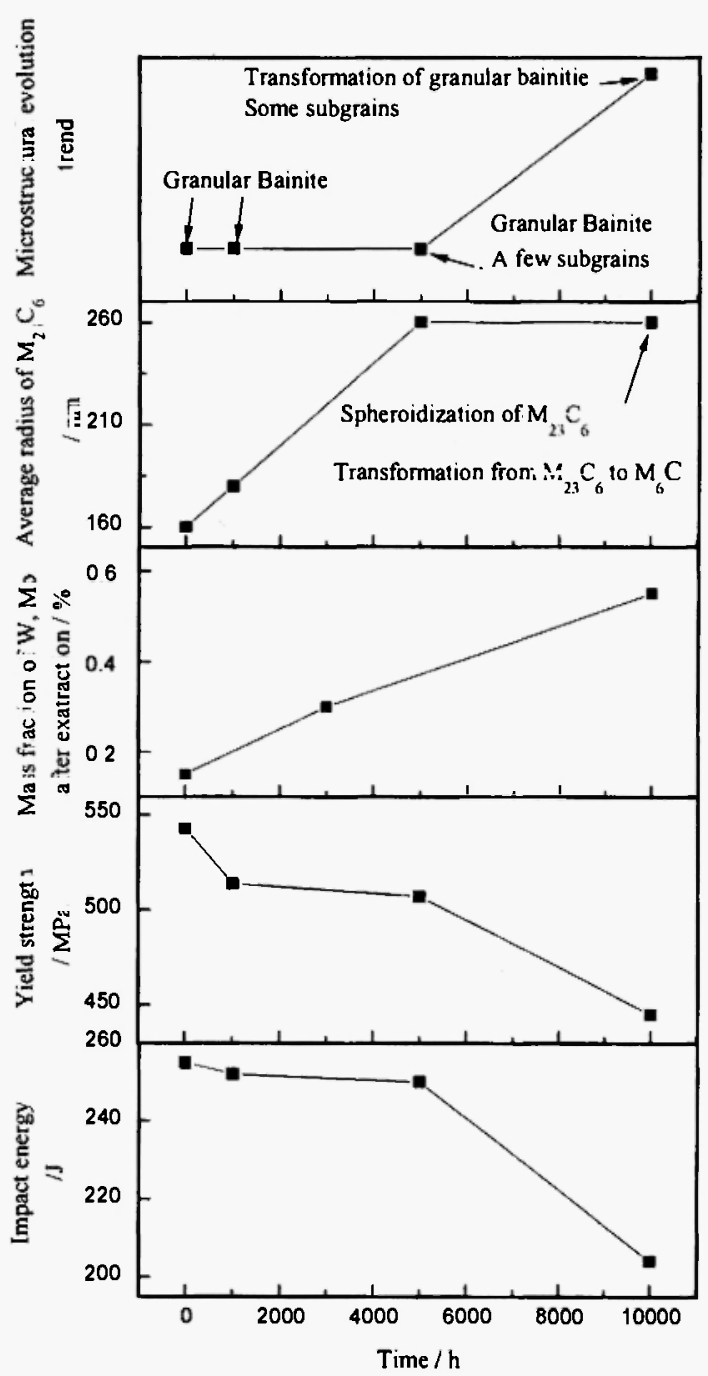

Fig. 7: The effect of main microstructural evolution on yield strength and impact toughness of T23 steel during aging at $873 \mathrm{~K}$

\section{CONCLUSIONS}

1. Yield strength, tensile strength and impact toughness of T23 steel tend to decrease during aging at $873 \mathrm{~K}$. Especially, after aged for $10000 \mathrm{~h}$ yield strength. tensile strength and impact toughness decrease by $18 \%$, 
$12 \%$ and $20 \%$ compared with the as-supplied materials.

2. During aging at $873 \mathrm{~K}, \mathrm{M}_{23} \mathrm{C}_{6}$ carbides coarsen gradually and many polygonal ferrites appear due to the coalescence of bainitic ferrite laths. The transformation from $\mathrm{M}_{23} \mathrm{C}_{6}$ to $\mathrm{M}_{6} \mathrm{C}$, spheroidization of $\mathrm{M}_{23} \mathrm{C}_{6}$, broadening of the martensite laths in carbon-rich islands and the formation of subgrains can also be observed. Otherwise there is a little change in the grain size and dislocation density.

3. There is an obvious decrease in yield strength and tensile strength when the aging time ranges from 0 to $1000 \mathrm{~h}$ and 5000 to $10000 \mathrm{~h}$. In the short-term region, coarsening of $\mathrm{M}_{23} \mathrm{C}_{6}$ carbide results in the significant degradation in the strength, whereas for long-term aging the transformation of granular bainitic ferrites becomes a key factor.

4. When T23 steel is aged at $873 \mathrm{~K}$ for $10000 \mathrm{~h}$, there is an obvious decrease in the impact toughness, which results from the coarsening of $\mathrm{M}_{23} \mathrm{C}_{6}$ and the coalescence of bainitic ferrite laths.

\section{REFERENCES}

1. W. Bendick, J. Gabrel, B. Hahn and B. Vandenberghe: Int. J. Press. Vessels Pip., 84, 13-20 (2007).

2. Young-Roc Im, Yong Jun Oh, Byeong-Joo Lee, Jun Hwa Hong and Hu-Chul Lee: J. Nucl. Mater, 297, 138 -148 (2001).
3. Lihui Zhu and Xueming Ma: J. Mater. Sci. Technol. , 19 (2), 126-128 (2003).

4. Nobuyoshi Komai, Toshiyuki Imazato and Fujimitsu Masuyama: ISIJ Int., Supplement, 41, S91-96 (2001).

5. R. L. Klueh, N.D.Evans, P. J. Maziasz and V. K. Sikka: Int. J. Press. Vessels Pip., 84, 29-36 (2007).

6. Kaori Miyata, Yoshiatsu Sawaragi, Hirokazu Okada, Fujimitsu Masuyama, Tomomitsu Yokoyama and Nobuyoshi Koma: ISIJ Int., 40 (11), 1156-1163 (2000).

7. Kaori Miyata, Masaaki Igarashi and Yoshiatsu Sawaragi: ISIJ Int. , 39 (9), 947-954 (1999).

8. A. J. Ardell: Metall. Trans., 16 A, 2131(1985).

9. L. M. Brown and R. K. Ham: in: Strengthening Methods in Crystals, edited by A. Kelly and R. B. Nicholson, John Wiley \& Sons Inc., New York, $1971 ;$ p. 12.

10. S. Esmaeili, D. J. Lloyd and W. J. Poole: Acta Mater. , 51, 2243-2257 (2003).

11. Kaori Miyata and Yoshiatsu Sawaragi: ISIJ Int., 41 (3), 281-289 (2001).

12. Jinghong Zheng, Zhengfeng Liang, Fufa Shen and Degang Yu: Shanghai Jiaotong Daxue Xuebao, 5, 78-88 (1985) (in Chinese).

13. H.K.D.H Bhadeshia and J.W. Christian: Metall.Trans., 21 A, 767-777 (1990). 
